\title{
Measurement of fat digestion in early life using a stable isotope breath test
}

MRC Dunn Nutrition Unit, Cambridge P McClean $M$ Harding W A Coward M R Green L T Weaver

Correspondence to: Dr P McClean, Department of Paediatrics and Child Health, St James's University Hospital, Beckett Street, Leeds LS9 7TF.

Accepted 28 May 1993

\author{
P McClean, M Harding, W A Coward, M R Green, L T Weaver
}

\begin{abstract}
${ }^{13} \mathrm{C}$ breath tests are a safe, non-invasive way of assessing nutrient digestion and absorption that can be used repeatedly in infancy and childhood. The aim of this study was to assess their value for measuring fat digestion in infants and young children with cystic fibrosis, and healthy controls whose pancreatic exocrine function is immature, and to monitor pancreatic enzyme supplementation.
\end{abstract}

Six infants with cystic fibrosis (aged 10-18 months) and nine healthy controls (aged 6-19 months) were studied. After an overnight fast each child ingested 7.5 $\mathrm{mg} / \mathrm{kg}^{13} \mathrm{C}$ trioctanoin (99 atom \% excess) followed by a known volume of milk. Breath samples were collected before and at 30 minute intervals thereafter for five hours. The ${ }^{13} \mathrm{C}$ enrichment of expired carbon dioxide was measured by gas isotope ratio mass spectrometry.

The mean (SD) percentage dose recovery of ${ }^{13} \mathrm{C}$ was $13.5(5 \cdot 3)$ for the cystic fibrosis group and $24 \cdot 2(6 \cdot 7)$ for the healthy controls. When those with cystic fibrosis were studied after supplementary pancreatic enzymes, the mean percentage dose recovery rose to $17 \cdot 1(6 \cdot 9)$. Total intraluminal lipolysis was diminished by $44 \%$ in young children with cystic fibrosis. Pancreatic enzyme supplements improved digestion by $27 \%$. The ${ }^{13} \mathrm{C}$ trioctanoin breath test was effective in detecting fat maldigestion and can be used to measure the benefits of enzyme supplements in early life.

(Arch Dis Child 1993; 69: 366-370)

The importance of maintaining optimal nutrition in children with chronic disease has been well recognised in recent years. Owing to diminished digestion, increased metabolic requirements and faecal losses the recommended energy requirements of children with cystic fibrosis are $20-50 \%$ above those of their healthy peers. There are often difficulties in ensuring that children with cystic fibrosis ingest and absorb enough energy to meet this target. Fat, the most energy dense nutrient in the diet, requires lipase for its digestion. Children with cystic fibrosis, because they have pancreatic exocrine deficiency, need extra lipase in the form of enzyme supplements. However, even with such enzyme supplementation, fat digestion may be incomplete. ${ }^{1}$ Patients are often started on enzyme supplements empirically, and the dose is manipulated on clinical grounds alone, because quantitative tests of fat digestion are invasive or unpleasant to perform, and it is not justified to submit children to them repeatedly.

${ }^{14} \mathrm{C}$ (radioactively labelled) breath tests have been used extensively in adults to detect fat malabsorption and to monitor the efficacy of enzyme supplementation and $\mathrm{H}_{2}$ antagonists on fat digestion. ${ }^{2}{ }^{3}$ Watkins et al modified them for use in children by replacing the radioactive isotope $\left({ }^{14} \mathrm{C}\right)$ with the stable isotope of carbon $\left({ }^{13} \mathrm{C}\right) .{ }^{4}$ After ingestion of the substrate the ${ }^{13} \mathrm{C}$ enrichment of expired carbon dioxide can be measured by gas isotope ratio mass spectrometry. To reduce the effects of gastric emptying on the rate of ${ }^{13} \mathrm{C}$ recovery Watkins et al administered the substrate to infants and children via a duodenal feeding tube. ${ }^{4}$ This obviously increased the invasiveness of the test. However, in a recent study of 4-8 year old children with cystic fibrosis in which ${ }^{13} \mathrm{C}$ labelled substrate was administered orally, depression of cumulative ${ }^{13} \mathrm{C}$ labelled carbon dioxide production $\left({ }^{13} \mathrm{CO}_{2}\right)$ due to delay in gastric emptying did not reduce the discriminatory value of the test. ${ }^{5}$

The physiology of fat digestion changes throughout the first two years of life: pancreatic lipase activity is diminished compared with older children, and preduodenal lipases assume greater importance. ${ }^{6}$ The aim of this study was to evaluate a modification of the ${ }^{13} \mathrm{C}$ fat breath test used by Murphy et al to discriminate between infants with pancreatic insufficiency and healthy controls, ${ }^{5}$ and to measure the benefits of enzyme supplementation in this age group, when the substrate was administered orally.

\section{Subjects and methods}

SUBJECTS

Six children with cystic fibrosis (aged 10-18 months) and nine healthy controls (aged 6-19 months) were studied. The children with cystic fibrosis were diagnosed in the neonatal period by blood immunoreactive trypsin screening followed by a confirmatory sweat test. At the time of the study they were all free of respiratory symptoms but had begun enzyme supplements for failure to thrive and/or steatorrhoea. Pancreatic insufficiency was confirmed by a modified version of the pancreolauryl test. ${ }^{7}$

\section{METHODS}

After an overnight fast each child ingested the substrate for the modified pancreolauryl test (fluorescein dilaurate/mannitol emulsion), 
Patient data and dose of lipase in supplement administered to children with cystic fibrosis

\begin{tabular}{lll}
\hline & $\begin{array}{l}\text { Controls } \\
(n=9)\end{array}$ & $\begin{array}{l}\text { Cystic fibrosis } \\
(n=6)\end{array}$ \\
\hline Sex (M:F) & $5: 4$ & $3: 3$ \\
Age range (months) & $6-19$ & $10-18$ \\
$\begin{array}{l}\text { Mean (SD) weight (kg) } \\
\begin{array}{c}\text { Median (range) dose of lipase } \\
\text { in supplement (BP units) } \\
\text { administered with test }\end{array}\end{array}$ & $9 \cdot 9(1 \cdot 9)$ & $10 \cdot 9(1 \cdot 9)$ \\
& & 12000 \\
& & $(4000-16000)$ \\
\hline
\end{tabular}

followed by $7.5 \mathrm{mg} / \mathrm{kg}$ of ${ }^{13} \mathrm{C}$ labelled trioctanoin (99 atom \% excess) (MSD Isotopes). This was diluted in a palatable long chain triglyceride emulsion (Calogen, Scientific Hospital Supplies; 1 gm trioctanoin was made up to $20 \mathrm{gm}$ of suspension with Calogen) and administered directly into the mouth with a syringe. Losses (collected in a weighed tissue) were taken into account when the dose ingested was calculated. The child then drank a known quantity of formula milk.

Breath samples were obtained before, and at 30 minute intervals after, administration of the substrate, for five hours using a facemask connected via two one way valves (Ambu Paedi valve) to a $600 \mathrm{ml}$ reusable oxygen reservoir bag (Laerdal) which had been fitted with a three way tap. Samples of $20 \mathrm{ml}$ of expired air were aspirated from the bag and stored in $20 \mathrm{ml}$ Vacutainers (Becton Dickenson) before measurement of the ${ }^{13} \mathrm{C} /{ }^{12} \mathrm{C}$ ratio by gas isotope ratio mass spectrometry (SIRA 10 VG Isogas, Middlewich, Cheshire). The child was allowed to feed 150 minutes after ingestion of the substrate, taking foods only of low ${ }^{13} \mathrm{C}$ abundance. A spot urine sample was collected between two and four hours to measure the fluorescein/ mannitol ratio and to confirm the presence of pancreatic insufficiency in the children with cystic fibrosis. The test was performed on two occasions in each child with cystic fibrosis, with and without enzyme supplementation. The dose of enzymes taken was the amount usually ingested with a snack meal (table).

MEASUREMENT OF ${ }^{13} \mathrm{C}$ ENRICHMENT

The ${ }^{13} \mathrm{C}$ enrichment of each sample was quoted as the relative difference (delta per mil $\%$ ) between the sample and the international limestone standard (Peedee Belemnite, PDB) ${ }^{8}$ where:

$$
\begin{aligned}
& \delta^{13}=\left[\left(R_{s} / R_{P D B}\right)-1\right] \times 10^{3} \\
& R_{s}={ }^{13} \mathrm{C} /{ }^{12} \mathrm{C} \text { in the sample } \\
& R_{\mathrm{PDB}}={ }^{13} \mathrm{C} /{ }^{12} \mathrm{C} \text { in } \mathrm{PDB}=0.0112372
\end{aligned}
$$

In the present experiments precision of duplicate analyses of breath samples was $0.09 \%$ SD.

The background variability of ${ }^{13} \mathrm{C}$ in breath was examined in three children (one healthy child and two children with cystic fibrosis who were studied with enzyme supplements) by giving all of the 'test feed' except ${ }^{13} \mathrm{C}$ trioctanoin. The variability (SD) over five hours was less than $0.7 \%$ in each case.

Fat digestion was expressed as the cumulative percentage dose recovered of ${ }^{13} \mathrm{C}$ from trioctanoin over five hours. ${ }^{9}$ The percentage dose recovered was calculated for each 30 minute interval as: percentage dose recovered for the interval $t$ to $t_{+1}(\mathrm{~min})=$

$\frac{\frac{\left(\delta^{13}{ }_{t}-\delta^{13}{ }_{o}\right)+\left(\delta^{13}{ }_{t+1}-\delta^{13}{ }_{o}\right)}{2} \times\left(t_{+1}-t\right) \times R_{P D B} \times 10^{-3} \times m^{2} \times 5}{\frac{\text { mg substrate }}{M W} \times \frac{P \times n}{100}} \times 100 \%$

where

$\frac{\left(\delta_{\mathrm{t}}-\delta_{\mathrm{o}}\right)+\left(\delta_{\mathrm{t}+1}-\delta_{\mathrm{o}}\right)}{2} \times\left(\mathrm{t}_{+1}-\mathrm{t}\right) \times \underset{\mathrm{PDB}}{{ }^{13} \mathrm{C} / \mathrm{mmol} \mathrm{CO}_{2} \text { for each time interval }}$

$\mathrm{mmol} \mathrm{CO} 2$ excreted $=5 \mathrm{mmol} / \mathrm{m}^{2} / \mathrm{min}^{10}$

$\mathrm{mmol}{ }^{13} \mathrm{C}$ administered $=\frac{\mathrm{mg} \text { substrate }}{\mathrm{MW}} \times \frac{\mathrm{P} \times \mathrm{n}}{100}$

$\mathrm{P}=$ atom $\%$ excess, $\mathrm{MW}=$ molecular weight, $\mathrm{n}=$ number of labelled carbon positions, and $\delta_{\mathrm{t}}$, $\delta_{t+1}, \delta_{o}$ are enrichments at times $t, t_{+1}$, and predose respectively.

To examine the reproducibility of the percentage dose recovered over five hours as a measure of fat digestion, the test was performed on three children (two healthy children and one child with cystic fibrosis studied with enzyme supplements) on two separate days. The coefficient of variation was $2 \cdot 7 \%$.

\section{STATISTICS}

The significance of the differences in the percentage dose recovered over five hours between the untreated children with cystic fibrosis and the healthy controls was tested using the non-parametric Mann-Whitney U test. The effect of enzyme supplementation on fat digestion was tested using a paired $t$ test.

Ethical approval for this study was obtained from the district ethics committee of Cambridge Health Authority.

\section{Results}

The ${ }^{13} \mathrm{C}$ enrichment of breath (in delta above baseline) and the cumulative percentage dose recovered from healthy control children and children with cystic fibrosis without enzyme supplements are shown in fig 1. Most control children demonstrated an early rise in ${ }^{13} \mathrm{C}$ excretion to a well defined peak at 50-150 minutes, but by the end of the test ${ }^{13} \mathrm{C}$ enrichment was close to zero compared with baseline values (fig $1 \mathrm{~A}$ ). One child (g) had a late peak (300 $\mathrm{min}$ ) which resulted in a low percentage dose recovered over five hours (fig 1C). The flattest curve (c) in fig 1A was from the 6 month old infant. In contrast most children with cystic fibrosis had low enrichments of ${ }^{13} \mathrm{C}$ in the breath, which gradually rose over the five hours (fig 1B). The mean (SD) time to, and height of the peak values for healthy children was $143.3(79.1) \mathrm{min}$ and $30.9(11.5)$ delta respectively, and $240(86.9) \mathrm{min}$ and $17 \cdot 3$ (6.5) delta respectively for the children with cystic fibrosis. Both of these differences were significant at $\mathrm{p}<0.05$. 

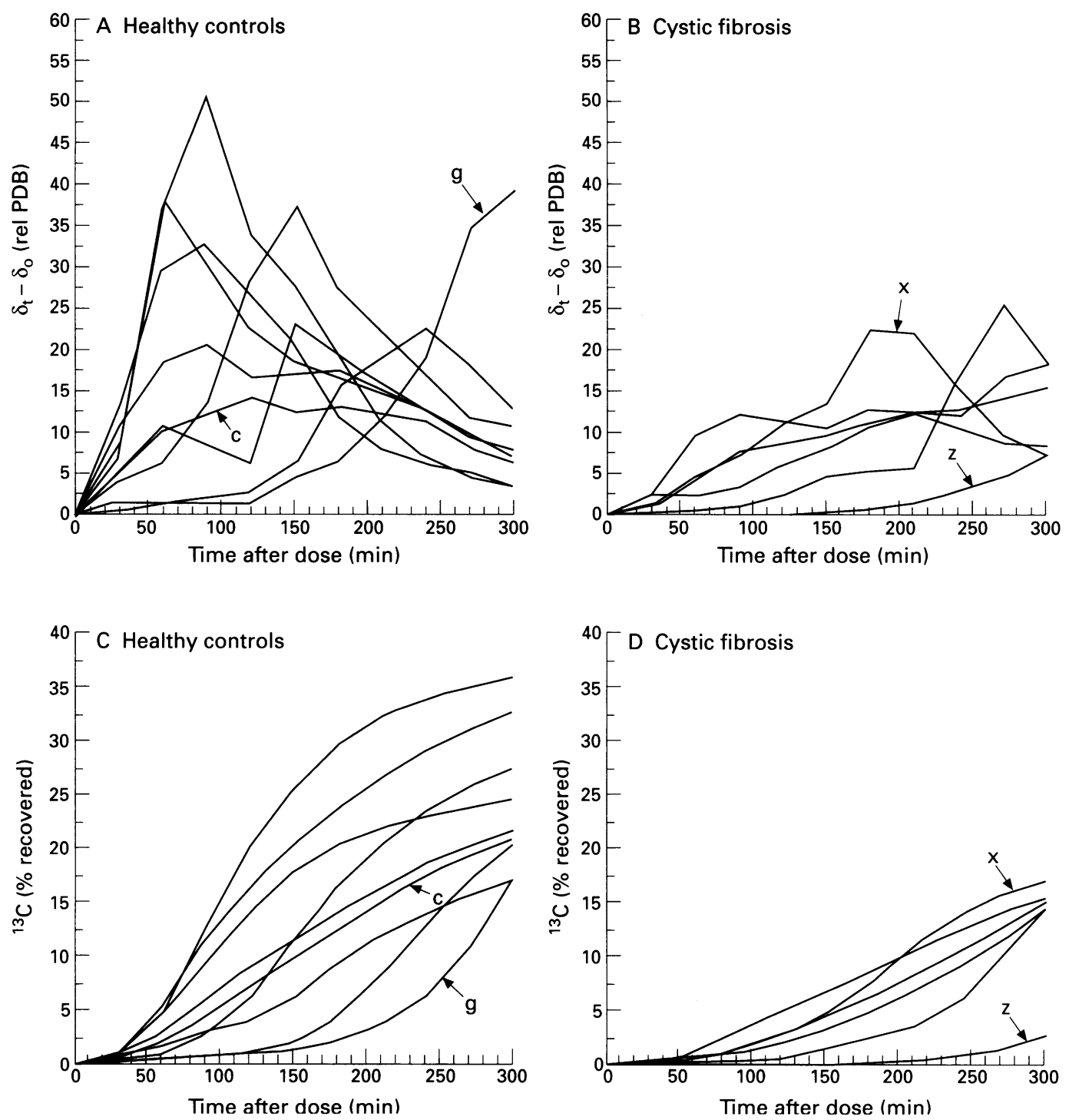

Figure $1(A)$ and $(B)$ show the ${ }^{13} C$ enrichment of breath carbon dioxide from healthy controls and children with cystic fibrosis after ingestion of ${ }^{13} \mathrm{C}$ trioctanoin. $(C)$ and $(D)$ represent the cumulative percentage dose recovered of ${ }^{13} C$ from the same children.

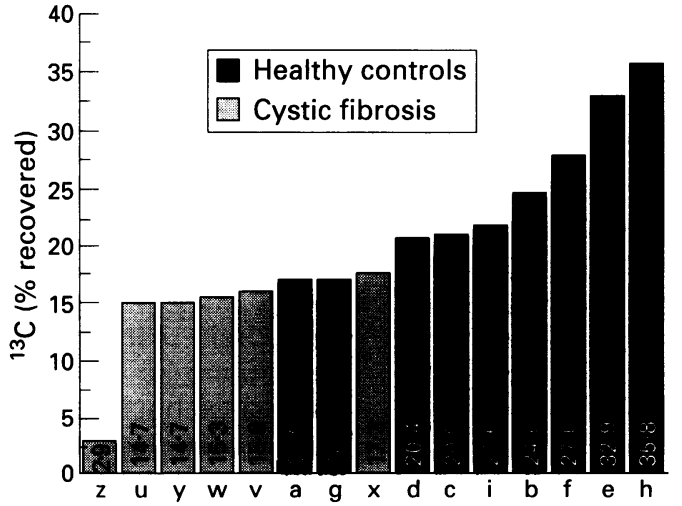

Figure 2 The percentage dose recovered over five hours of ${ }^{13} \mathrm{C}$ from ${ }^{13} \mathrm{C}$ trioctanoin in healthy controls $(a-i)$ and in children with cystic fibrosis $(u-z)$. Mean $(S D)$ values were $24 \cdot 2(6 \cdot 7)$ for controls and $13 \cdot 5(5 \cdot 3)$ for children with cystic fibrosis $(p<0 \cdot 01)$.

Figure 2 shows the percentage dose recovery of ${ }^{13} \mathrm{C}$ over five hours in controls and children with cystic fibrosis. The mean (SD) values for the controls and children with cystic fibrosis were $24.2(6.7)$ and $13.5(5.3)$ respectively $(p<0 \cdot 01)$. Even when the child with cystic fibrosis with very low recovery (z) was excluded the differences remain significant $(\mathrm{p}<0.05)$.

When the test was repeated on the children with cystic fibrosis with the addition of enzyme supplements, the mean time to the peak value shortened slightly from $240.0(86.9) \mathrm{min}$ to $195.0(72.7)$ min (not significant), but there was no difference in the peak heights $(17 \cdot 3$ (6.5) delta without and 17.5 (8.9) with enzymes). However, the mean percentage dose recovery increased from $13.5(5.3)$ to $17 \cdot 1$ $(6.9)$ - that is by $27 \%$ above untreated values $(\mathrm{p}<0.05)$ (fig 3). The child whose percentage dose recovery did not increase with the addition of enzyme supplements ( $x$ ) had the highest percentage dose recovery (without enzymes) in the cystic fibrosis group: just inside the range of the healthy control group.

\section{Discussion}

We have shown, using a ${ }^{13} \mathrm{C}$ fat breath test, that intraluminal lipolysis is diminished by $44 \%$ in young children with cystic fibrosis. Pancreatic enzyme supplements improve digestion by $27 \%$. This study provides further 


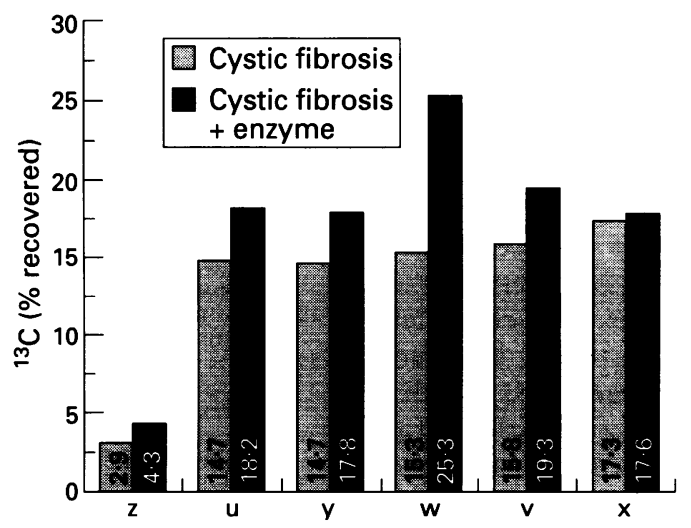

Figure 3 The percentage dose recovered over five hours in each child with cystic fibrosis when the test was performed without and with the ingestion of enzyme supplements. Mean (SD) values without enzymes were 13.5 (5.3) and with enzymes $17 \cdot 1$ (6.9) $(p<0 \cdot 05)$.

evidence that stable isotope breath tests can be used to demonstrate fat maldigestion even in young children. The differences in cumulative ${ }^{13} \mathrm{C}$ production between the control children and those with cystic fibrosis were not as wide as those noted by Murphy et al in a comparable study of older children. ${ }^{5}$ In that study, the mean sum of ${ }^{13} \mathrm{C}$ production over four hours in patients and controls was $36 \cdot 8 \%$ and $176.9 \%$ respectively, whereas in our study the values were $60 \cdot 5 \%$ and $122 \cdot 3 \%$ respectively. The lower cumulative ${ }^{13} \mathrm{CO}_{2}$ production in healthy infants compared with older children is probably related to small body size (which would become obvious if it were possible to compare percentage doses recovered in both studies) but may also reflect immaturity of pancreatic lipolytic activity. ${ }^{6} 11$ The higher production of ${ }^{13} \mathrm{CO}_{2}$ in infants compared with older children with cystic fibrosis may be due to some residual pancreatic function ${ }^{12}$ and/or to a greater contribution of preduodenal lipase to fat digestion in this age group. ${ }^{13} 14$

The rate of ${ }^{13} \mathrm{CO}_{2}$ production from children with cystic fibrosis was slow and still rising at the end of the test in three subjects (fig 1B). This has been noted in previous studies ${ }^{59}$ and may reflect ongoing fat digestion by preduodenal lipase further down the small intestine. This enzyme remains active in the more acidic environment of the gut lumen of the child with cystic fibrosis.

The failure to distinguish unequivocally between normal children and those with depressed pancreatic function should not be seen as a deficiency of the test, but rather a reflection of the interplay of physiological maturation and pathological damage of the pancreas on the results. Pancreatic lipase activity is low at birth in all children ${ }^{6}$ and, in those we have studied, declining pancreatic function from cystic fibrosis occurs in the face of normal maturation.

The enhanced recovery of ${ }^{13} \mathrm{C}$ in children with cystic fibrosis who were taking enzyme supplements was less than expected when compared with fat balance studies ${ }^{14}$ and with earlier studies using the ${ }^{13} \mathrm{C}$ labelled fat breath tests in adults, ${ }^{15}$ older children, ${ }^{5}$ and in infants when the substrate was given directly into the duodenum. ${ }^{4}$ Again total intraluminal lipolysis (that is the effect of pancreatic and preduodenal lipases) was depressed less in young infants with cystic fibrosis than in older children, and the addition of pancreatic enzymes (which cannot realise their optimum activity at the low $\mathrm{pH}$ in the gut lumen of the child with cystic fibrosis) may not cause a large improvement in digestion. This is borne out by the lack of increase in ${ }^{13} \mathrm{C}$ recovery with the addition of enzyme supplements to the child whose percentage dose recovered was already just within the range of the healthy control group. However, further studies on the effect of increasing doses of enzyme supplements on ${ }^{13} \mathrm{C}$ recovery should be done.

We have ascribed the differences in ${ }^{13} \mathrm{C}$ recovery between normal children and those with cystic fibrosis to differences in intraluminal fat digestion. We have assumed that absorption, oxidation, and carbon dioxide production rates were similar in the two groups. Histological and functional abnormalities of the intestinal mucosa in cystic fibrosis have been well documented. ${ }^{16}$ Depletion of the bile salt pool through increased faecal losses and increased production of glycine rather than taurine conjugates contribute to fat malabsorption. ${ }^{17}$ However, as a medium chain fatty acid, the absorption of octanoic acid is dependent neither on the concentration of bile salts in the duodenum nor on mucosal integrity, ${ }^{18}$ and once absorbed it is completely oxidised. ${ }^{19}$

Because it was impractical to measure carbon dioxide production rates by indirect calorimetry in these children, we assumed a constant average value for carbon dioxide production of $5 \mathrm{mmol} / \mathrm{m}^{2} / \mathrm{min},{ }^{10}$ as is common practice in stable isotope studies. Carbon dioxide production is increased by significant pulmonary disease, exercise, and high dietary carbohydrate loads. ${ }^{20}$ The children were studied after an overnight fast and did not take part in any strenuous activities during the test. None of the patients with cystic fibrosis had respiratory symptoms. The debate continues over whether there is a fundamental defect in energy metabolism in children with cystic fibrosis which is unrelated to pulmonary function, infection, and nutritional status. ${ }^{21} 22$ Such a defect might result in increased carbon dioxide production. However, in a recent study of asymptomatic infants with cystic fibrosis, total energy expenditure was the same as that measured in age matched controls. ${ }^{23}$ Our assumption, therefore, that carbon dioxide production rates in infants with cystic fibrosis with no respiratory symptoms are not significantly different to those of healthy infants is justified. We concluded that the factor responsible for the changes in ${ }^{13} \mathrm{C}$ recovery that we described was intraluminal lipolysis.

This stable isotope breath test can detect fat maldigestion and is acceptable as a safe, repeatable, non-invasive test for assessment of enzyme supplementation and other therapeutic interventions, even in infants and young children with cystic fibrosis. In this age group, however, when pancreatic exocrine function 
is immature and preduodenal lipase makes an important contribution to intraluminal lipolysis even in healthy children, the test may not discriminate completely between healthy children and those with cystic fibrosis. Cholesteryl octanoate is not hydrolysed by preduodenal lipase, and may be a more effective substrate for discriminating between the two groups of children. However, ${ }^{13} \mathrm{C}$ cholesteryl octanoate remains expensive to buy compared with ${ }^{13} \mathrm{C}$ trioctanoin. Nevertheless, with a growing interest in the use of stable isotope labelled substrates in many fields of medical research, it is likely that they will become increasingly available for the investigation and management of patients with pancreatic insufficiency and other causes of digestive disease.

Dr McClean was supported by a grant from the Northern Ireland Council for Postgraduate Medical Education.

1 Beverley DW, Kelleher J, MacDonald A, Littlewood JM, Robinson T, Walters MP. Comparison of four pancreatic extracts in cystic fibrosis. Arch Dis Child 1987; 62: 564-8.
Newcomer AD, Hofmann AF, DiMagno EP, Thomas PJ,

2 Newcomer AD, Hofmann AF, DiMagno EP, Thomas PJ, Carlson GL. Triolein breath test: a sensitive and specific 6-13.

3 Mundlos S, Kühnelt P, Adler G. Monitoring enzyme replacement treatment in exocrine pancreatic insufficiency using the cholesteryl octanoate breath test. Gut 1990; 31: 1324-8.

4 Watkins JB, Schoeller DA, Klein PD, Ott DG, Newcomer AD, Hofmann AF. ${ }^{13}$ C-trioctanoin: a nonradioactive $\mathrm{AD}$, Hofmann AF. ${ }^{3} \mathrm{C}$-trioctanoin: a nonradioactive breath test to detect

5 Murphy MS, Eastham EJ, Nelson R, Aynsley-Green A. Non-invasive assessment of intraluminal lipolysis using a ${ }^{13} \mathrm{CO}_{2}$ breath test. Arch Dis Child 1990; 65: 574-8.

6 McClean P, Weaver LT. Ontogeny of human pancreatic exocrine function. Arch Dis Child 1993; 68: 62-5.

7 Green MR, Austin S, Weaver LT. A simplified test of exocrine pancreatic function in childhood. Pediatric Reviews and Communications $1991 ; 41: 269$.
8 Craig H. Isotopic standards for carbon and oxygen and corrective factors for mass-spectrometric analysis of carbon dioxide. Geochimica Cosmochimica Acta 1957; 12: 133-49.

9 Watkins JB, Klein PD, Schoeller DA, Kirschner BS, Park R, Perman JA. Diagnosis and differentiation of fat malabsorption in children using ${ }^{13} \mathrm{C}$-labelled lipids: trioctanoin triolein and palmitic acid breath tests. Gastroenterology 1982; 82: 911-7.

10 Shreeve WW, Cerasi E, Luft R. Metabolism of $\left[2-^{14} \mathrm{C}\right]$ pyruvate in normal, acromegalic and HGH-treated human subjects. Acta Endocrinologica 1970; 65: 155-69.

11 Lebenthal E, Lee PC. Development of functional response in human exocrine pancreas. Pediatrics 1980; 66: 556-60.

12 Waters D, Dorney S, Gruca M, Brown J, Gaskin K Pancreatic sufficiency in CF infants from a neonatal Pancreatic sufficiency in CF infants from a neonatal
screening programme. Proceedings of the 10th International screening programme. Proceedings of the 10th International
Cystic Fibrosis Congress. Sydney, Australia 1988, Excerpta Medica. Asia Pacific Congress Series 74: 162.

13 Hamosh M, Scanlon JW, Ganot D, Likel M, Scanlon KB Hamosh P. Fat digestion in the newborn: characterization of lipase in gastric aspirates of premature and term infants. 7 Clin Invest 1981; 67: 838-46.

14 Hamosh M, Klaeveman HL, Wolf RO, Scow RO. Pharyngeal lipase digestion of dietary triglyceride in man. Pharyngeal lipase digestion of

15 Vantrappen GR, Rutgeerts PJ, Ghoos YF, Hiele MI. Mixed triglyceride breath test: a non-invasive test of pancreatic lipase activity in the duodenum. Gastroenterology 1989; 96: 1126-34.

16 Eggermont $\mathrm{E}$. The role of the small intestine in cystic fibrosis patients. Acta Paediatr Scand 1985; 317 (suppl): 16-21.

17 Roy CC, Weber AM, Lepage G, Smith L, Levy E. Digestive and absorptive phase anomalies associated with the exocrine pancreatic insufficiency of cystic fibrosis. 7 Pediatr Gastroenterol Nutr 1988; 7 (suppl 1): S1-7.

18 Shiau YF. Lipid digestion and absorption. In: Johnston LR ed. Physiology of the gastrointestinal tract. New York: Raven ed. Physiology of the gastro

19 Schwabe AD, Bennett LR, Bowman LP. Octanoic acid absorption and oxidation in humans. Appl Physiol 1964; 19: $335-7$

20 Kane RE, Hobbs P. Energy and respiratory metabolism in cystic fibrosis: the influence of carbohydrate content of nutritional supplements. $\mathcal{F}$ Pediatr Gastroenterol Nutr 1991; 12: 217-23.

21 O'Rawe A, McIntosh I, Dodge JA, et al. Increased energy expenditure in cystic fibrosis is associated with specific mutations. Clin Sci 1992; 82: 71-6.

22 Vaisman N, Pencharz PB, Corey M, Canny GJ, Hahn E. Energy expenditure of patients with cystic fibrosis. Energy expenditure of patient $1987 ; 111: 496-500$.

23 Davies PSW, Bronstein MN. Energy expenditure of infants with cystic fibrosis. Pediatr Pulmonol 1992; 8 (suppl): 